\title{
REVIEW ON: USES OF CEREALS IN TRADITIONAL FOODS OF NEPAL AND THEIR PREPARATION PROCESS
}

\author{
Anish Dangal $\bowtie$ \\ Nilgiri College, Tribhuvan University \\ E W, E-W Hwy, Itahari, Nepal, 56705 \\ anishdangal42@gmail.com \\ Prekshya Timsina \\ Central Campus of Technology \\ Sangam Dahal \\ Central Department of Food Technology \\ ${ }^{1}$ Tribhuvan University \\ Bijayapur Sadak, Dharan, Nepal, 56700
}

$\triangle$ Corresponding author

\begin{abstract}
The purpose of research was to make people aware about traditional foods of Nepal and use of cereals in traditional foods.

Nepal, country is home for people of many races, ethnicity and religion. This country is rich in natural beauty and traditional beliefs and practices. In Nepal, the primary occupation of many people is agriculture. Cereals like finger millet, buckwheat etc. are among the underutilized crops in this country. Nepal is rich in traditional and indigenous foods because of the richness in ethnic diversity. During the research we came to know that traditional food is attached to emotional and cultural level for the old generational residents of this country, but this trend seems to be decreasing in today's generation due to Western culture influence and modernization. During preparation the process followed was still same as followed decades ago. The advancement in food technologies can be followed by the advancement in traditional foods for their own benefits. We should protect and promote our traditional foods, as it is deeply rooted with our cultural aspects; which results in preservation of culture and traditions. This article is about the use of cereals in traditional food of Nepal and their preparation process.
\end{abstract}

Keywords: cereals, Nepal traditional foods, ethnic groups, preparation process, indigenous foods.

DOI: $10.21303 / 2504-5695.2021 .002122$

\section{Introduction}

Nepal is multicultural, multilingual and multi-religious and under-developing country with maximum agricultural base, where varieties of indigenous and traditional food culture are still being consumed locally [1]. The ethnic groups are deeply lodged in their tradition and culture with rich in indigenous knowledge [2]. Traditional foods are foods and dishes, passed through generations and have been consumed by multiplex generations. It is generally considered, that "traditional food" refers to food with a particular raw material, and/or with a particular recipe and preparation process, known from decades [3]. Traditional foods and beverages are mainly produced as homebuilt, and a few by restaurants and small manufacturers, and by large food processing plant facilities [4]. Industrialization of food production, European laws on food safety and even the development of innovative products necessitate the characterization of the typical sensory characteristics of the traditional products [3].

Ethnic groups of Nepal consume a variety of traditional fermented and nonfermented foods. Masyaura, Fulaura, Jilebi, Sel roti, Kinema, Gundruk, Sinki, Khalpi, Mesu, Chhurpi, Dahi, Mahi, Ghiu, Jandh, and Rakshi are some of the main fermented traditional foods and beverages, whereas Chiura, Makai-Bhatmas, Dalmodh, Bhujiya, Khir, Dhakane, Puwa, Kasar, Jimbu, Khoa, ChookAmilo, Chaku, Shakhar, and Chiuri-Ghiu are some of the major non-fermented traditional foods [5]. In a simple word, traditional foods are foods, consumed in the way our ancestors ate them. Traditional foods are about choosing the simplest food options available within our budget and location. Traditional foods are directly associated with the standards and beliefs of a particular grouping [6]. 
Thus, the purpose of research is to make people aware about traditional foods of Nepal and use of cereals in traditional foods.

\section{Materials and Methods}

This study used extensive interviews with people of different ethnic groups during field visits. The study also reviewed scientific publications, peer-reviewed journal articles, thesis, conference papers, project reports, and government reports in a systemic way. Screening of all papers was by reading the titles, followed by abstracts, and reading the complete paper if found relevant. The research also extracted information, especially evidences or key messages from the available resources.

\section{Results}

About 20-30 people from Brahmin, Chettri, Tamang, Limbu, Rai, Newar, Maithili group and Tharu community of different places were interviewed to generate general information about their traditional foods and the preparation process they follow.

\section{1. Production of Cereals}

Agriculture takes an important place in Nepalese economy as about $60.4 \%$ of population is engaged in agriculture for their livelihood [7]. Along with generating employment, agriculture also supports national economy by contributing $33 \%$ in Gross Domestic Production (GDP). Nepalese agriculture, though diversified, is generally dominated by three major cereal crops, i.e., rice, wheat and maize (Table 1), which jointly rate $30.92 \%$ of Agricultural GDP of the country [7]. These crops are important for maintaining food security of the country.

Table 1

Agricultural production of Nepal 2075/76 (2018/19)

$\begin{array}{ccc}\text { Crops } & \text { Area, hectare (ha) } & \text { Production, metric ton } \\ \text { Paddy } & 1,491,744 & 5,610,011 \\ \text { Maize } & 956,447 & 2,713,635 \\ \text { Wheat } & 703,992 & 2,005,665 \\ \text { Millet } & 263,261 & 314,225 \\ \text { Barley } & 24,409 & 30,550 \\ \text { Buckwheat } & 10,311 & 11,464 \\ \text { Total } & 3,450,163 & 10,685,550\end{array}$

Note: the table is based on data [8]

The country's adequacy in food grain produces has not been achieved as its growth could not keep pace with extending demand for food. Nepal is positioned $72^{\text {nd }}$, with Global Hunger Index (GHI) of 22.0 among the world countries [9]. Cereal crops have achieved major place in addressing food security issues in Nepal. In recent years there have been inconstancies in crop production and demands situations due to many reasons [10]. The major challenges of Nepalese agriculture and food security at present are:

1) extending use of agriculture land for non-agricultural purposes;

2) increase in out-migration of economically active population;

3) negative effect of climate change;

4) scarce use of quality fertilizer;

5) limited use of upgraded technologies;

6) small and fragmented lands that hinder mechanization and commercialization [11].

There's a huge gap in yield of cereal crops, which is about $1 \mathrm{t} / \mathrm{ha}$ between the research station and the farmers' field, however, minimization of the yield gaps by Research and Development sector, can improve the food security in the country.

Some of the major traditional foods are described below. 


\section{2. Sel roti}

Sel roti is a popular food item in religious, festivals and ritual processes among Nepalese. Rice, sugar and frying medium like ghee, oil or vegetable fat are major constituents of Sel roti [12]. It's a doughnut-shaped, deep-fried rice based confectionary item, indigenous to Nepal [13]. Sel roti; an indigenous non- alcoholic fermented cereal product of Nepal is a deep-fat fried, puffed and of circular shape, resembling doughnut [14].

The shelf life is really short because of high moisture content; the product goes moldy rapidly soon. The flour should be neither too fine nor too coarse. In the traditional recipe, the size of the flour is manipulated by jolting nanglo in an inclined position. The oversized particles that roll down the nanglo are collected and grinded again to fine size. The selroti, prepared as shown in Fig. 1, is characteristically puffed and cooked well.

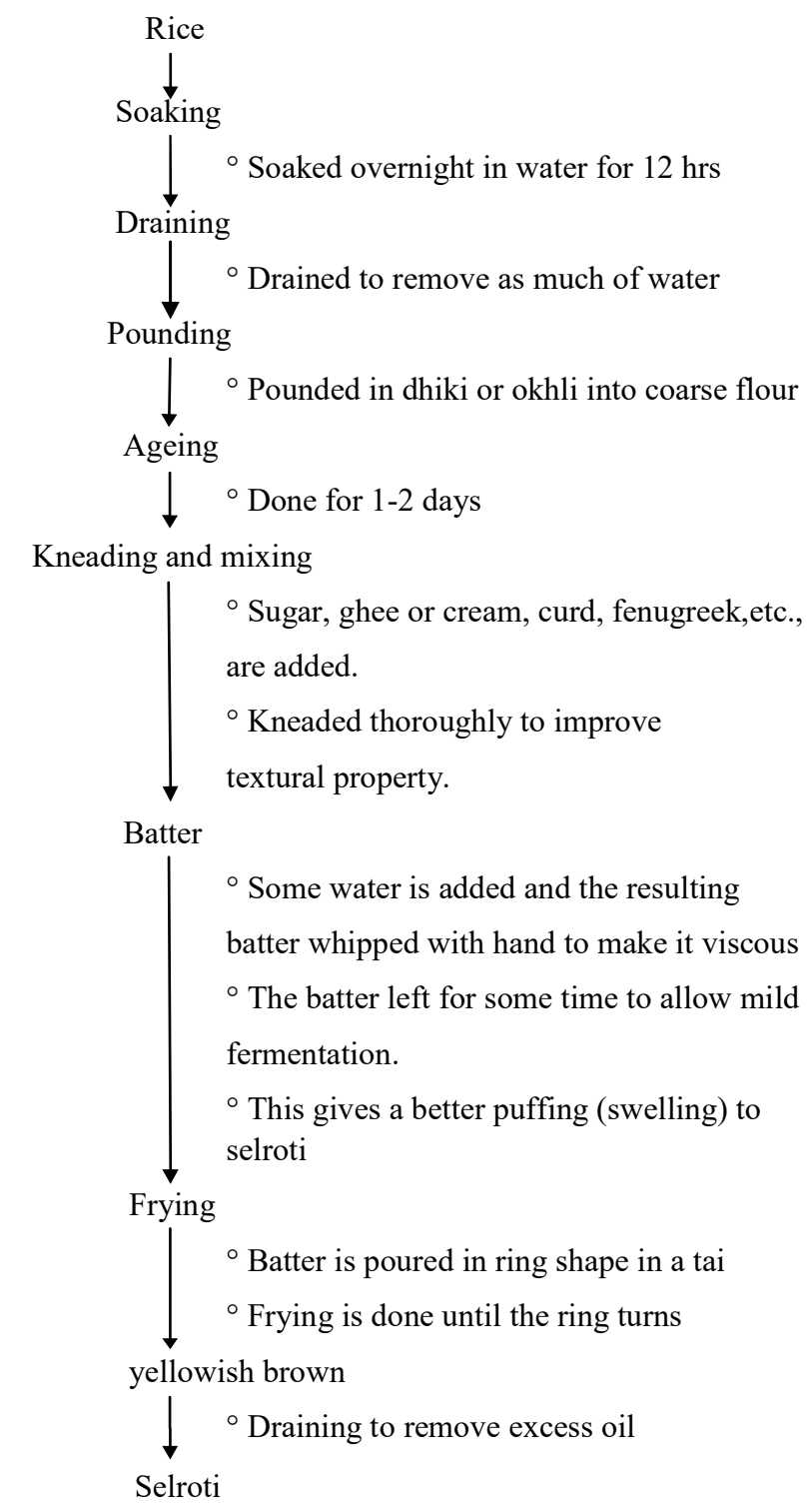

Fig. 1. Improved method of Sel roti preparation

The shelf life of selroti, prepared by this method, is longer than that by following traditional recipe and can remain edible for about 15 days (without mold). Sel roti is taken out of tai with the of help of a bamboo skewer, also known as "jheer". The fat is drained, and selroti is kept in a container, which tastes exceptionally good if served hot [1]. 


\section{3. Bhakka}

Bhakka is a steam-cooked cereal product, prepared from coarse rice flour (Fig. 2). The product is indigenous to the Tharu community of the Terai but is enjoyed by all.

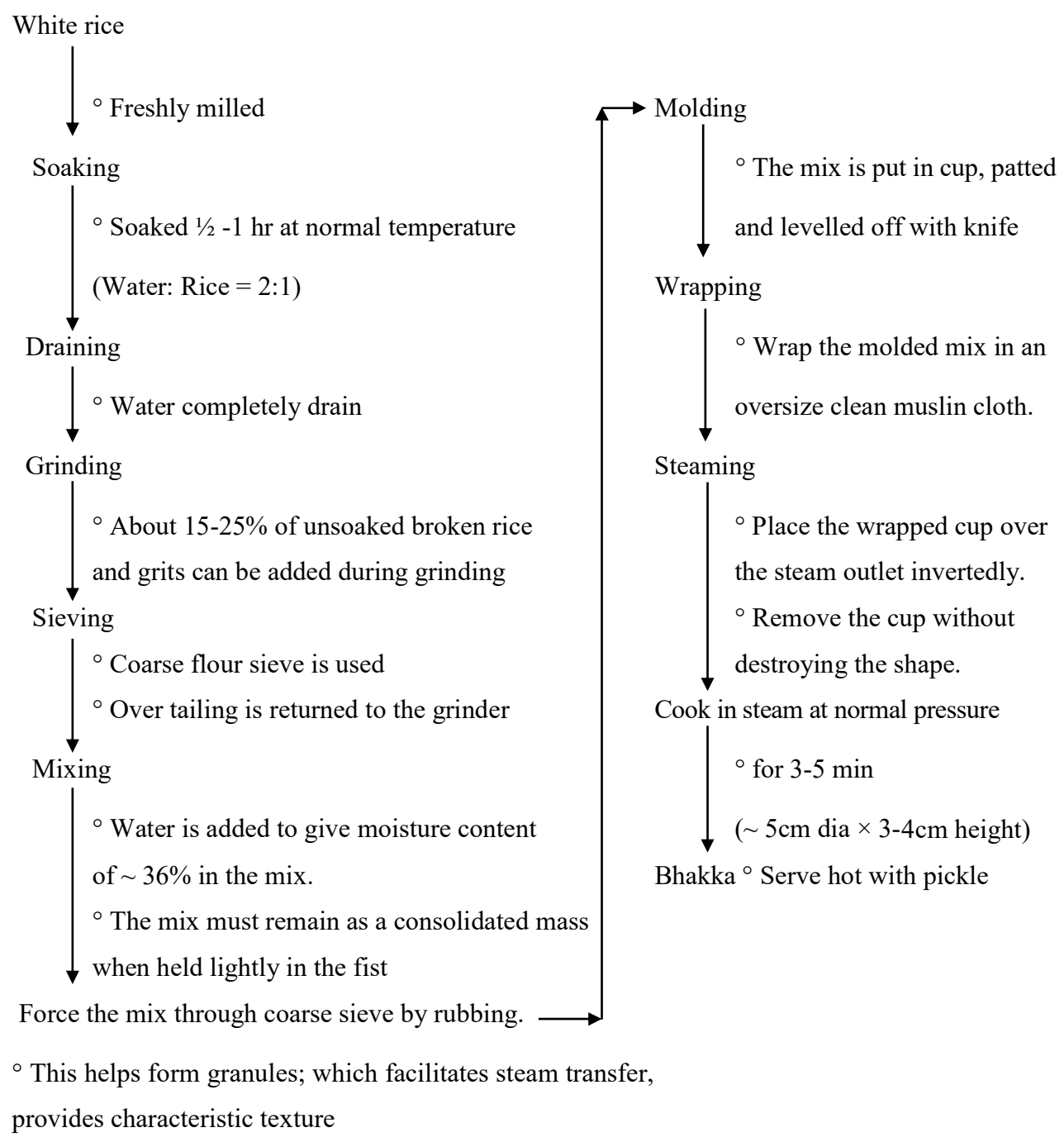

Fig. 2. Preparation of Bhakka

Bhakka is mianly to be relished during the winter season mostly from November to February. The term "bhakka" must have come from a pair of native words bhaff (=vapor/steam) and khabe (=to eat). It is generally consumed hot in the form of breakfast. The product can be stored for 1-2 days without spoilage but not without the loss of characteristic sensory properties [1].

\section{4. Dhindo}

Dhindo is traditionally made from buckwheat or millet flour but wheat, corn flour can also be used as well [15]. Dhindo can be prepared from any grain as long as it is ground into flour as it is simple to make. An iron pan, also known as "Phalame Tapke", is used for cookery. A narrow iron spatula, known as "Dabilo", is used to stir the thick mix as it makes stirring easier. Dhindo is eaten by making a small ball with one's fingers, dipping it in lentil or meat soup, milk, gundruk etc. as per one's choice and swallowed without chewing and also can be served with chutney [16]. The process of making dhido, as shown in Fig. 3, is called "Maskaaune" [17]. 


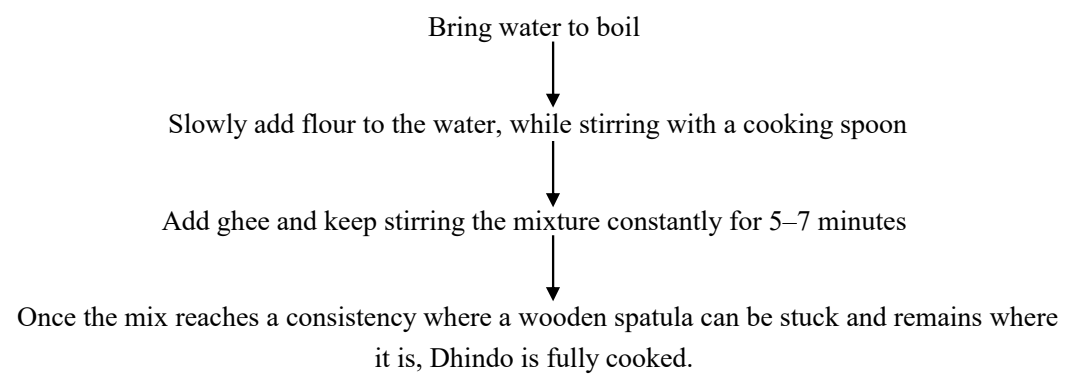

Fig. 3. Preparation of dhindo

\section{5. Bhuja or Murai}

Bhuja is a puffed rice product, having nutritional value similar to that of rice, is generally consumed as snack in the Terai region of Nepal. The word murai is decided from the term murra, which means "puffed". It's generally used by the Tharu and Chaudhari ethnical groups of Nepal as a really important food item in marriage form, celebrations and other occasions. Murai is also used for the preparation of chatpate; a spicy snack and other items; as it goes well with every variety of dishes. It's generally produced from long variety rice Oryzae indica [18]. Its preparation process is shown in Fig. 4.

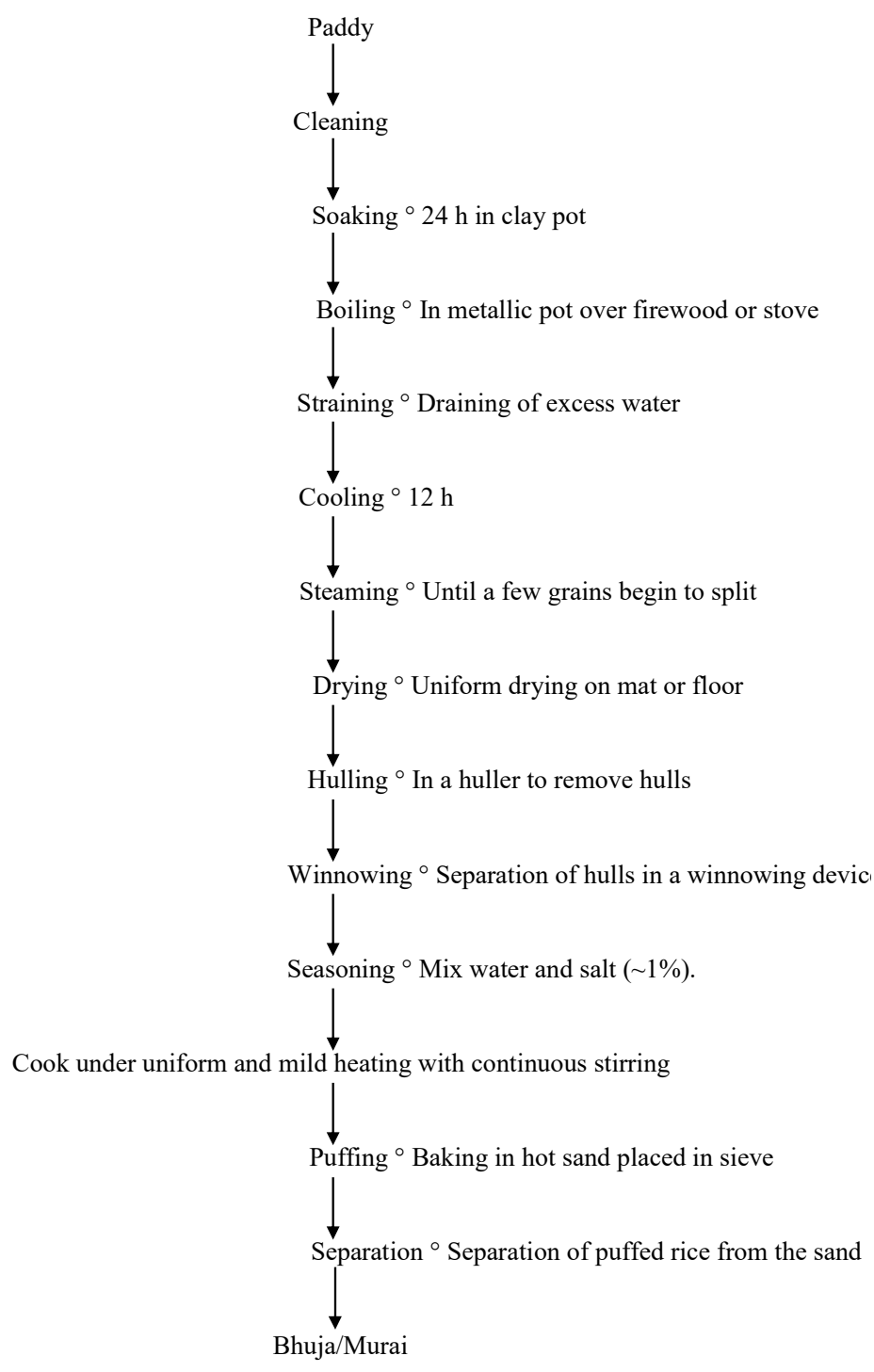

Fig. 4. Preparation of bhuja/murai by the traditional method 


\section{6. Chiura}

Chiura or beaten rice flakes is pre-cooked with crispy texture, and is in a ready-to-serve form, is a very common food item in cuisines of Nepal. It is taken as a snack or as full meal with achar (pickle), chutney, meat, eggs, vegetables, beans, etc. It can also be found in other Southeast Asian countries like India, Bangladesh, Bhutan and Pakistan. It is popular in all communities, especially in Newar, Brahmin, Chettri, Rajbanshi, Choudhari, etc. Coarse varieties of rice are specially chosen for preparation of chiura. Chiura is taken as major item in celebrations like marriage, festivals, picnic and party. Researches show that chiura making process as shown in Fig. 5 incurs loss of minerals like calcium and iron and some studies have been performed on the fortification to compensate the loss of these minerals [18].

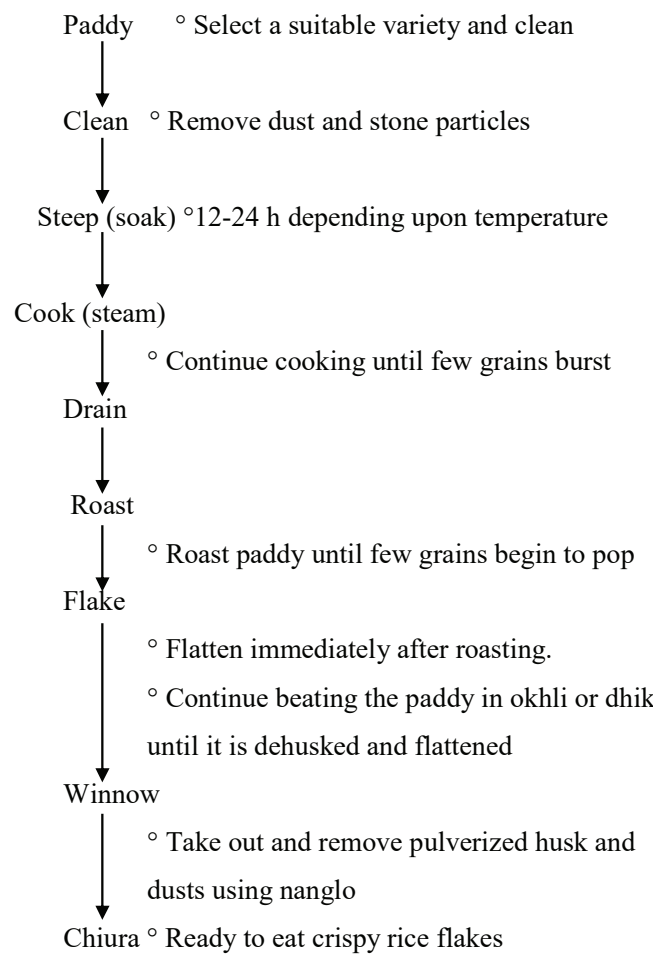

Fig. 5. Preparation of chiura by the traditional method

\section{7. Rakshi and Jandh}

Jandh and Rakshi are traditional alcoholic products of almost all Mangarantis (includes Magar, Gurung, Rai, Limbu, Sherpa, Bhote, and Lepcha Castes) and Tibetans. Jandh is a slightly acidic and sweet alcoholic beverage, and prepared as shown in Fig. 6, while Rakshi is the distillate from fermenting mash and prepared as shown in Fig. 7.

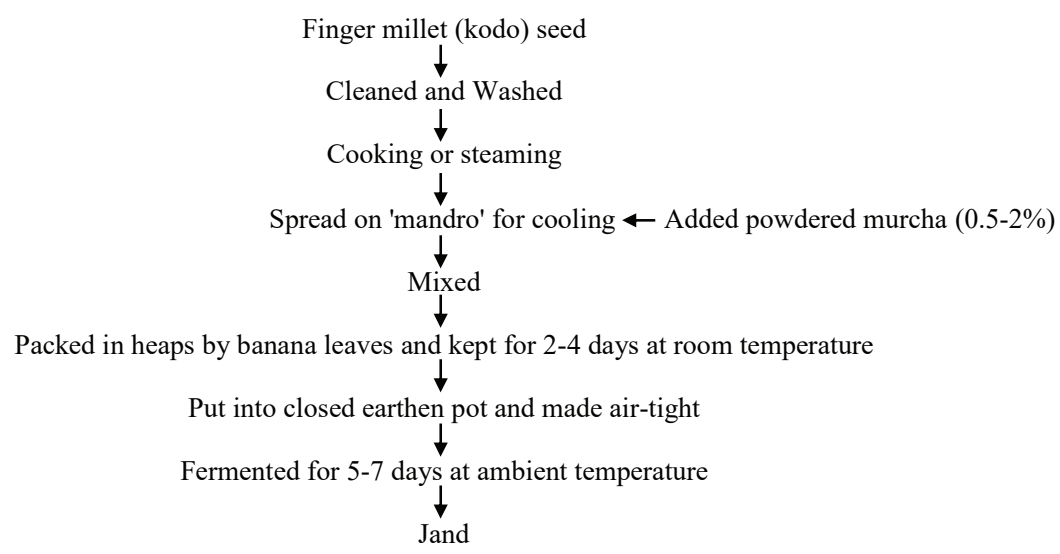

Fig. 6. Traditional method of preparation of Jandh 


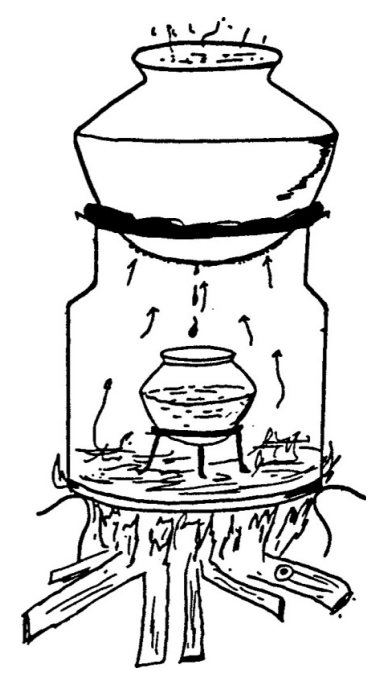

Fig. 7. Traditional method of raksi distillation, showing distillate as being collected to a small metallic vessel, kept above the stand inside the main cylindrical container

Jandh is a fermentation product of finger millet (Eleusine coracana), also known as Ragi whereas rice is for preparation of Rakshi [5]. The finger millet seeds are sometimes supplemented with a small amount of wheat or corn grains [19]. This beverage is assumed to be a good tonic, particularly for postnatal women [20]. The study by [21] suggested that mold, followed by yeast and lactic, were important organisms, imparting pleasant flavor, taste, and organoleptic characteristics to the final fermented product. The fermentation process not only aids development of flavor, savory taste, and texture in the food, but also enriches the substrate with protein, essential amino acids, essential fatty acids, and vitamins [22].

\section{8. Tongba}

Tongba is a millet-based alcoholic beverage with high traditional and indigenous value among the Limbu people of eastern Nepal, found in the eastern mountainous region of Nepal. Tongba is culturally and religiously important to the Limbu people of eastern Nepal [23]. The premium destination for consuming Tongba is Taplejung. Tongba is taken as a symbol of respect and provided to the guest among the Limbu people and considered an important beverage for special occasions and festivals. Tongba actually is the vessel, as shown in Fig. 8, which holds the fermented millet beverage, known as "mandokpenaa thee" [24] and the preparation process is shown in Fig. 9.

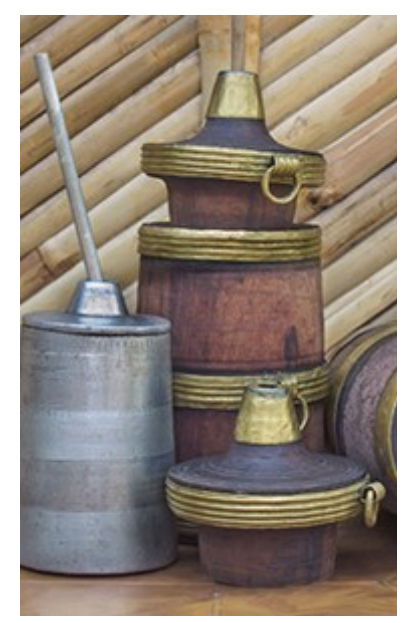

Fig. 8. Tongba vessel 
Whole grain millet

Cooling of cooked millet and mixed with source of bacteria, molds and yeast

The mass is collected and placed in a woven bamboo basket lined with green leaves or plastic

Covered with thick fold of cloth and allowed to remain in a warm place for 1-2 days depending upon the temperature.

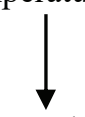

The sweet mass is then packed tightly into an earthenware pot or plastic jars and the opening is usually sealed off to prevent air from entering.

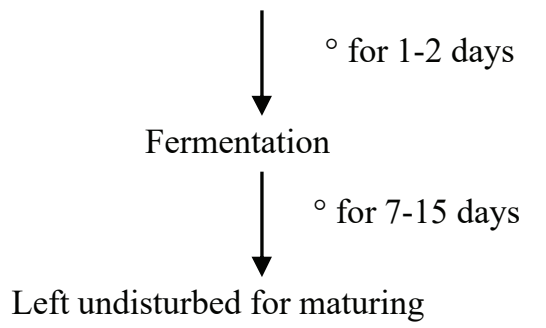

Left undisturbed for maturing

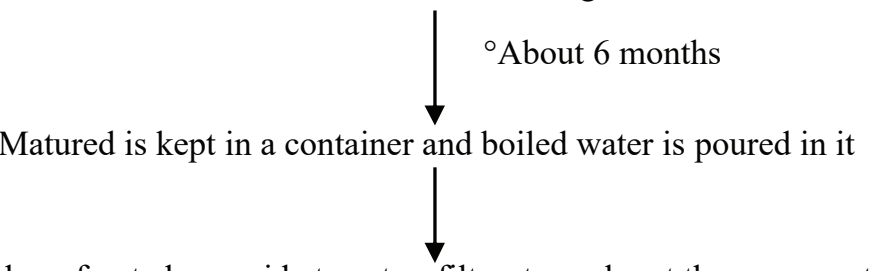

Bamboo straw is used, perforated on a side to act as filter; to suck out the warm water and alcohol from the millet grains

More hot water is added and the process is repeated until the alcohol exhausts

Fig. 9. Preparation of Tongba

\section{9. Bagiya and Yamari}

Bagiya is prepared especially by Maithili groups, while Yamari is a very popular festive dish, traditionally prepared during post-harvest celebration of Yamari Punhi or Dhanya Purnima, indigenous to the Newari community of Nepal. Yamari is the product, prepared from cooked jaggery and lightly roasted sesame seed mixture, enclosed within rice flour dough and steamed till cooked. Since it is prepared from rice, sesame and jaggery, enriching with minerals and vitamins will help in advancement towards being more nutritious and can help to minimize the protein energy malnutrition (PEM) problem of Nepal. However, the calorific value of the product was found to be low [10]. The festival starts during full moon from December to January, the people of Kathmandu worship the goddess of grains, Annapurna for good harvest and enjoy a grand feast after all the hard work of the harvesting season. Yamari 
is prepared and offered ritualistically to the gods. The festival is followed mainly in the Newar farming community, however today it is observed in almost every Newari home [25]. Bagiya is prepared almost in a similar way to that of yamari as shown in Fig. 10.

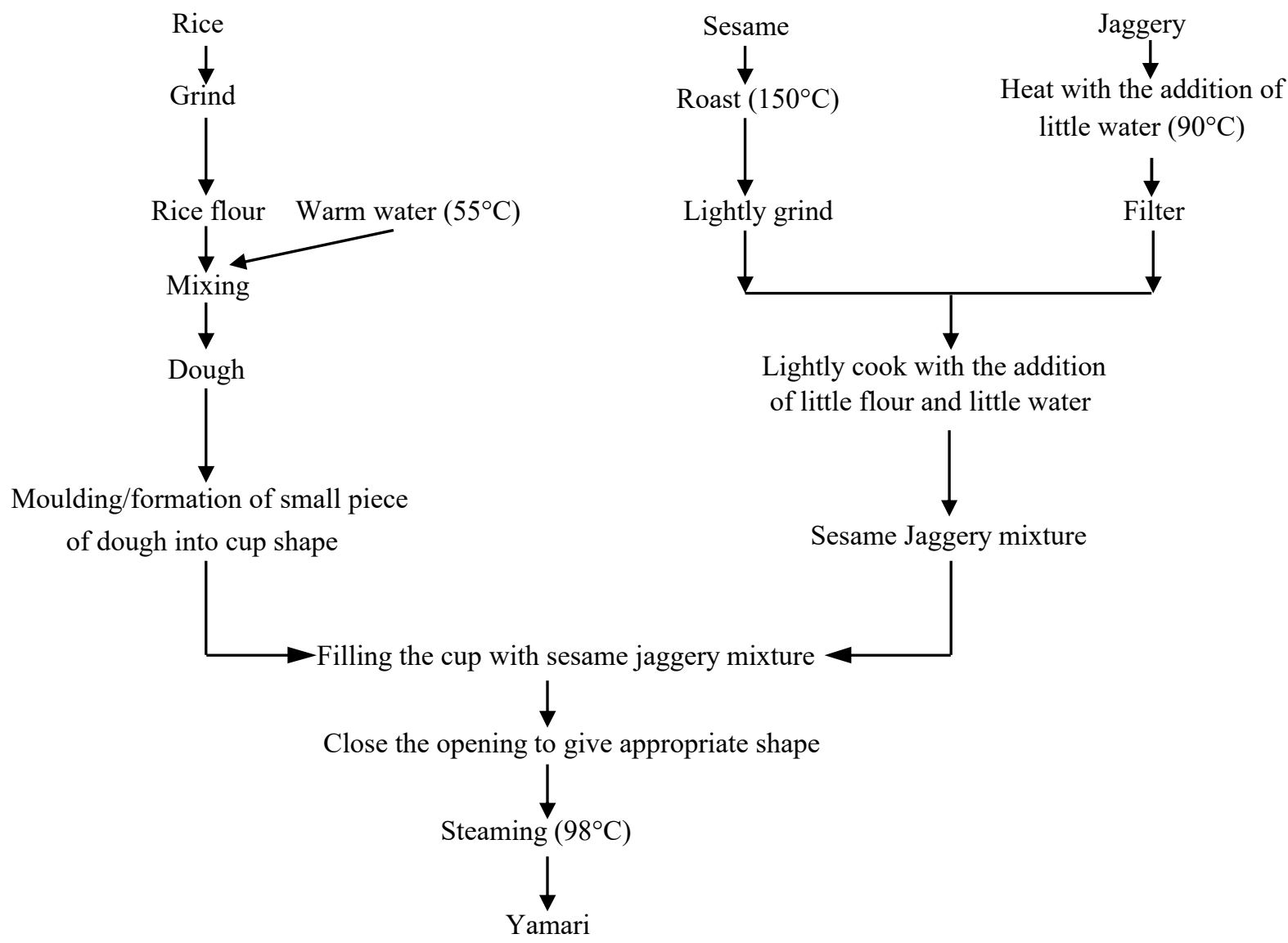

Fig. 10. General method of Yamari preparation

\section{10. Kasaar}

Kasaar is an oval or a ball-shaped confection, made from jaggery (25-30 \% by mass) and roasted rice (70-75\% by mass), prepared especially in the Brahmin and Chettri communities, and is considered an indispensable item in wedding ceremony and other similar ceremonies. Since, the product is an intermediate moisture food; it has a shelf life of several months [1]. The making process is simple as the roasted rice flour and jaggery are mixed together and rolled in hand until it takes shape of a small ball.

\section{11. Khajuri and Thekua}

Thekua is the normal food, which is a sweet product with less nutrient contents, is indigenous to Maithili communities of terai region of Nepal and is typically utilized in several occasions, festivals, rituals, offerings and as special foods on big day; especially on the occasion of Chhat festival. It is a deep-fried product, viewed as a precursor of western biscuits, prepared by mixing of white flour, sugar, ghee and few spices [26]. Khajuri is referred to as indigenous cookies, proposed as a good way to use composite flours because they are ready-to-eat, have a good energy source, and are widely eaten worldwide. The word cookies, or biscuits, as they are called in many parts of the world, usually refers to a baked good, containing the three main ingredients: flour, sugar and fat. In Khajuri and Thekua, the same ingredients follow, except that the product is baked [26] as shown in Fig. 11. 


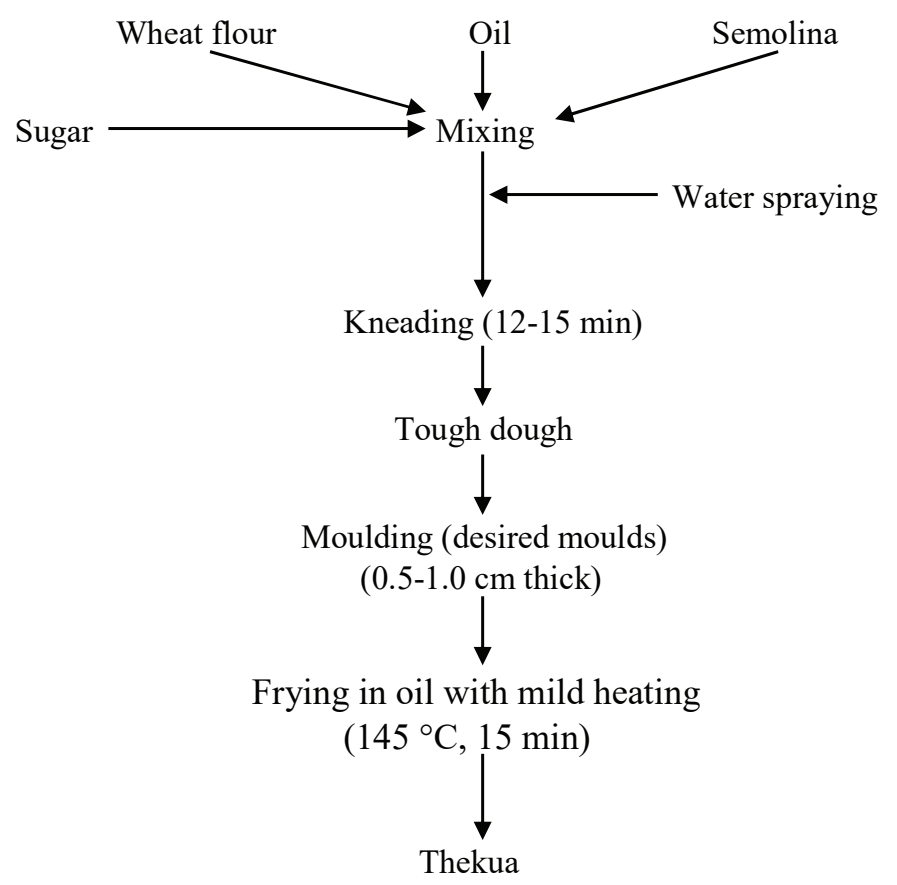

Fig. 11. Preparation process of Thekua

\section{Limitations of the research results}

No qualitative and quantitative analysis was performed.

Advanced or improved methods of all traditional foods weren't included.

No detailed information was made available due to time constraints during the survey.

\section{Recommendation}

The traditional preparation process has got some of their drawbacks, so advancement of the preparation process and researches are required.

Nutritional value and shelf life of traditional foods can be increased.

\section{Findings}

This study highlights the present status of cereal used traditional foods of Nepal and the preparation process, being followed till date.

Special thanks to [5] and [18] and the survey conducted, we came to know about the traditional practices, being followed, and collection of information, which resulted in need of some advancement in the preparation process.

The former studies didn't cover the broad varieties of cereal based traditional foods, which has been included in this study.

The main goal of introducing the cereal based traditional foods has been accomplished and has been introduced with their preparation process.

Researches can be performed and the traditional foods can be introduced with advancement in their preparation process, which can enhance the taste, nutrient quality and shelf life of the traditional foods.

\section{Conclusions}

Traditional foods can play a great role in nutrient fulfillment during food insecurity. It also has got its historical importance as it carries our history from ages. It's like a gift, handed to us by our ancestors, which we should hand to the upcoming generations. Preserving the traditional foods also aid to the preservation of our culture. Many traditional foods are facing problems due to introduction of Western foods. If the current trend is to continue, many of our traditional foods will 
soon be lost forever. Possible modifications can be done in order to commercialize our traditional foods, so that we can increase the economic standard of our people and country and our tradition, culture and history can be introduced to the whole world. Being a student of food technology, it's our duty and responsibility to preserve and promote our traditional foods.

In the course of the research, we have obtained that still old methods are used for the preparation of traditional foods, which has got drawbacks in themselves.

The results of the research will be useful in introduction of traditional foods of Nepal and the preparation process, maked available for the people to try and enjoy the foods around the globe, which may help in promotion of traditional foods and their preservation.

\section{Authors' contribution}

This work was completed with equal contribution of authors. Author Anish Dangal wrote the first draft, performed the survey, managed the validation and supervision. Author Prekshya Timsina performed the survey, managed the references, supervision and validation. Author Sangam Dahal prepared the first draft, managed the references and validation.

\section{Acknowledgements}

The Authors are very grateful to late Mr. Kali Prasad Dangal and Mr. Mahesh Timsina. They will forever be remembered for their abundance support and love.

\section{References}

[1] Kharel, G. P., Rai, B. K., Acharya, P. P. (2010). Traditional Foods of Nepal. Highlight Publication Pvt Ltd.

[2] Acharya (Siwakoti), E., Pokhrel, B. (1970). Ethno-Medicinal Plants Used by Bantar of Bhaudaha, Morang, Nepal. Our Nature, 4 (1), 96-103. doi: https://doi.org/10.3126/on.v4i1.508

[3] Cayot, N. (2007). Sensory quality of traditional foods. Food Chemistry, 101 (1), 154-162. doi: https://doi.org/10.1016/ j.foodchem.2006.01.012

[4] Kristbergsson, K., Oliveira, J. (Eds.) (2016). Traditional Foods: General and Consumer Aspects. Springer, 416. doi: https://oi.org/ 10.1007/978-1-4899-7648-2

[5] Dahal, N. R., Karki, T. B., Swamylingappa, B., Li, Q., Gu, G. (2005). Traditional Foods and Beverages of Nepal - A Review. Food Reviews International, 21 (1), 1-25. doi: https://doi.org/10.1081/fri-200040579

[6] Dangal, A. (2019). Cereal Based Unfermented Traditional Foods of Nepal and Its Importance. Nilgiri College.

[7] MoAD (2015). Statistical Information on Nepalese Agriculture. Ministry of Agriculture Development, Singh Durbar, Kathmandu, Nepal.

[8] MoALD. Statistical Information on Nepalese Agriculture 2075/76 (2018/19) (2020). Government of Nepal, Ministry of Agriculture \& Livestock Development, Planning \& Development, Cooperation, Coordination Division, Statistics and Analysis Section, Singha Durbar: Kathmandu, Nepal. Available at: http://doanepal.gov.np/downloadfile/Statistical\%20information\%20 on\%20Nepalese\%20agriculture_1601976502.pdf

[9] 2017 global hunger index: The inequalities of hunger (2017). International Food Policy Research Institute (IFPRI). doi: https:// doi.org/10.2499/9780896292710

[10] Shrestha, O. (2012). Preparation and quality evaluation of yamari. B. Tech. Dissertation. Tribhuvan Univ.

[11] Amgain, L., Timsina, J. (2005). Major Agronomical Research Works at the Institute of Agriculture and Animal Sciences, Rampur, Chitwan, Nepal: A Review. Journal of the Institute of Agriculture and Animal Science, 26, 1-20. doi: https://doi. org/10.3126/jiaas.v26i0.606

[12] Katawal, S. B., Subba, D. (2017). Effect of Frying Medium on the Quality of Sel-roti. Himalayan Journal of Science and Technology, 1, 45-48. doi: https://doi.org/10.3126/hijost.vli0.25822

[13] Yonzan, H., Tamang, J. P. (2009). Traditional processing of Selroti - a cereal based ethnic fermented food of the Nepalis. Indian Journal of Traditional Knowledge, 8 (1), 110-114.

[14] Dahal, S., Katawal, S. B. (2014). Effect of Batter Ageing on Microbial, Physiochemical Changes and Sensory Quality of Sel-roti. Journal of Food Science and Technology Nepal, 8, 12-17. doi: https://doi.org/10.3126/jfstn.v8i0.11721

[15] Sherchand, K. (2001). A global buckwheat trading. Research and Development on buckwheat: An important yet a neglected crop in Nepal. Proc. National workshop. Kathmandu, 19-28.

[16] Centre for Indigenous Peoples' Nutrition and Environment. Available at: https://www.mcgill.ca/cine/research/food/benefits

[17] How to make Dhido. Available at: http://www.weallnepali.com/recipe/special-items/how-to-make-dhido-dhidom 
[18] Rai, B. K., Kharel, G. P., Acharya, P. P. (2007). Handbook of Traditional Foods of Nepal. Highland Publication.

[19] Gajurel, C., Baidya, K. (1979). Rakshi jandh technol. Traditional Technology of Nepal (in Nepalese). Kathmandu: Trivuwan University, 175-190.

[20] Tamang, J. P., Sarkar, P. K., Hesseltine, C. W. (1988). Traditional fermented foods and beverages of Darjeeling and Sikkim-a review. Journal of the Science of Food and Agriculture, 44 (4), 375-385. doi: https://doi.org/10.1002/jsfa.2740440410

[21] Shrestha, A. K., Noomhorm, A. (2002). Comparison of physico-chemical properties of biscuits supplemented with soy and kinema flours. International Journal of Food Science and Technology, 37 (4), 361-368. doi: https://doi.org/10.1046/j.1365-2621.2002.00574.x

[22] Beuchat, L. R.; Doyle, M. P., Beuchat, C. R., Montville, T. J., (Eds.) (1997). Traditional fermented foods. Food Microbiology Fundamentals and Frontiers. Washington, D.C.: American Society for Microbiology, 629-648.

[23] Baird, L. (2011). Nepalese Cooking. lulu.com, 56.

[24] Tamang, J. P. (Ed.) (2016). Ethnic Fermented Foods and Alcoholic Beverages of Asia. Springer, 409. doi: https://doi.org/ 10.1007/978-81-322-2800-4

[25] Pathak, J. (2015). Yomari or Yoh-Mari. Taste of Nepal. Available at: http://tasteofnepal.blogspot.com/2015/07/yomari-or-yohmari.html

[26] Suman, A. (2012). Optimization of Formulation and Process for the Preparation of Khajuri (A Maithili Indigenous Food). Tribhuvan University.

How to cite: Dangal, A., Timsina, P., Dahal, S. (2021). Review on: uses of cereals in traditional foods of Nepal and their preparation process. EUREKA: Life Sciences, 6, 49-60. doi: https://doi.org/10.21303/2504-5695.2021.002122 